\title{
Odnos forme i funkcije u arhitekturi baroknog razdoblja
}

AвStRact: Botica Dubravka, Odnos forme i funkcije u arhitekturi baroknog razdoblja (Form and Function in Baroque Architecture). "Poznańskie Studia Slawistyczne" 13. Poznań 2017. Publishing House of the Poznan Society for the Advancement of the Arts and Sciences, pp. 303-315 . ISSN 2084-3011.

The paper presents relations between form and function in the architecture on few selected examples of theoretical texts. Interrelation of form and function is analyzed on examples of the most important types of baroque architecture - the castle and the church. Baroque castle has a key role in the creation and validation of the power of rulers, enfilade rooms and ceremonial staircase have function of stage on which the ruler displays himself and his power, but also at the same time, reflects strictly hierarchical social system of baroque. In religious architecture, relations between form and function are more regulated. In Instructiones... (1577) of the Council of Trent, the emphasis in the design has been placed on the fulfillment of the functions of post-Tridentine liturgy, from the layout of plan to the new meaning of the triumphal arch. However, the regulations are most clearly expressed at the end of the 18th century, in demand for functionality as the primary goal of a sacred space. Following the adoption of Enlightenment ideas in Central Europe, churches are build according to claim that their design should be "useful and purposeful", according to the request of Joseph II.

KeYwords: architectural treatise; baroque; castle; church; post-Tridentine church; $18^{\text {th }}$ century

Vjerojatno najpoznatija sintagma koja se veže za odnos forme i funkcije u arhitekturi je Form Follows Function, forma slijedi funkciju, a koja je odredila i temeljne smjernice razvoja arhitekture 20. stoljeća. Njezin autor, američki arhitekt Louis Sullivan (1856.-1924.), upotrijebio ju je u tekstu The Tall Office Building Artistically Considered iz 1896. godine' Promatrajući prirodne zakonitosti, Sullivan naglašava da u svakoj pojavi

${ }^{1}$,It is the pervading law of all things organic and inorganic, of all things physical and metaphysical, of all things human and all things superhuman, of all true manifestations of the head, of the heart, of the soul, that the life is recognizable in its expression, that form ever follows function. This is the law". Cit. prema O'Gorman, 1991, 15. 
u prirodi forma slijedi funkciju, što je nužno primijeniti i u arhitekturi. Ističe utilitarnost kao temelj dobrog dizajna, odnosno projekta, koji ispunjava sve potrebe i funkcije: „To make an architecture that fitted its function - a realistic architecture based on well defined utilitarian needs - that all practical demands of utility should be paramount as basis of planning and design"'. Odbacujući dekorativni repertoar i prevladane kanone prošlih razdoblja, arhitekti naglašavaju funkcionalnost arhitekture kao primarni zahtjev. Posebno su te tendencije bile izražene u razdoblju međuratne moderne, na školi Bauhausa, ali i u razdoblju obnove 1950-ih.

No naglašavanje funkcionalnosti kao glavne odrednice arhitekture, iz koje proizlazi i sama forma i oblikovanje, iako dominanto u 20. stoljeću, nikako se ne može vezati samo uz novija razdoblja. Za razliku od svih drugih umjetničkih vrsta, arhitektura je nužno najviše određena funkcijom jer ima prije svega i praktičnu namjenu. Proces nastanka arhitektonskog djela daleko je složeniji od procesa stvaranja slike ili skulpture, uključuje više sudionika - od naručitelja, arhitekta, često i autora programa, graditelja, pa do samih izvođača radova - te je znatno dugotrajniji i skuplji. Već i zbog tih okolnosti razumljivo je da se o funkciji, namjeni arhitekture kao bitnoj odrednici procesa nastanka govori već od samih početaka, a njima se bave i prvi tekstovi o arhitekturi. U najpoznatijem arhitektonskom traktatu iz antike, u Vitruvijevom De Architectura Libri Decem ${ }^{3}$, jasno se iskazuje međusobna uvjetovanost forme i funkcije u arhitekturi. Vitruvije u deset knjiga razrađuje različite aspekte arhitekture, od školovanja arhitekata, teoretskih pojmova, teze o nastanku arhitekture, tipologije i vrsta arhitekture, do redova i dekoracija. U drugom poglavlju prve knjige ističe tri uvjeta koje arhitektura mora ispunjavati: firmitas, utilitas i venustas. Arhitektura tako mora biti čvrsta i solidno građena, treba biti svrsishodna te lijepa i skladna, odnosno dekorirana primjereno funkciji ${ }^{4}$. Funkcija određuje formu arhitekture, u ovom slučaju hrama, tako će za hramove posvećene ženskim božicama biti primjerena centralna tlocrtna forma, dorski

${ }^{2}$ Iz Sullivan, The Autobiography, cit. prema Kruft, 1986, 411.

${ }^{3}$ Marcus Vitruvius Pollio (oko 84.-15. pr. Kr.), vojni graditelj u Cezarovoj vojsci, za vrijeme Oktavijana radi rimski sustav vodovoda, v. Kruft, 1986, 20-21.

${ }^{4}$ Venustas razrađuje na šest pojmova: ordinatio, dispositio, eurythmia, symmetria, decor i distributio. Zadnja dva pojma, decor i distributio, uže se odnose na temu odnosa forme i funkcije u arhitekturi v. Kruft, 1986, 24-25. 
hramovi bit će posvećeni Minervi, Marsu i Heraklu, a korintski Veneri, Flori i nimfama.

Vitruvijeva razmatranja bila su poznata i u srednjem vijeku, no prvo sustavno čitanje i njihova primjena zaživjela je tek u ranoj renesansi, razdoblju obilježenom izuzetnim teoretskim interesom za arhitekturu. Leon Battista Alberti (1404.-1472.), najutjecajniji teoretičar arhitekture 15. stoljeća, oslanjajući se na Vitruvija, piše traktat u deset knjiga De Re Aedificatoria, dovršen 1452. godine. Preuzima Vitruvijeve kategorije firmitas, utilitas i venustas kao glavne odlike dobre arhitekture, a ljepotu građevine definira kao sklad cjeline u aristotelovskoj tradiciji ${ }^{5}$. No bavi se i praktičnim pitanjima, poput smještaja, okruženja, zidova i krova, prozora građevine, sve do dekoracija, materijala i njegove primjene ${ }^{6}$. Posebno se, oslanjajući se ne samo na Vitruvija nego i na srednjovjekovne pisce ${ }^{7}$, usredotočuje na funkciju građevine. Razrađuje pojam utilitas razlikujući prema namjeni različite tipove građevine, prostornu kompoziciju, primjerene dekoracije i proporcije. Napominje i da se arhitektura mora ugledati na prirodu i njene zakonitosti, treba ih slijediti, ali svaka je specifična i sebi svojstvena ${ }^{8}$. Albertijev traktat utjecao je na sve kasnije pisce, no tijekom 16. stoljeća zamjetan je manje izražen teoretski karakter u arhitektonskim traktatima koji sve više postaju knjige uputa i primjera. Najbolje to ilustrira devet knjiga o arhitekturi Sebastiana Serlija (1475.-1554.), prva - Regole generali di architettura... - objavljena je 1537. godine. Pisana jednostavnim jezikom, ta bogato ilustrirana uputa za arhitekte, zahvaljujući i brojnim

${ }^{5},(\ldots)$ a harmony of all the parts (...) fitted together with such proportion and connection, that nothing could be added, diminished or altered, but for the worse", cit. prema De Zurko, 1957, 142.

${ }^{6}$ Šest osnovnih elemenata arhitekture: regio, area, partitio (tlocrt), paries, tectum, apertio; Kruft, 1986, 48.

${ }^{7}$ De Zurko, 1957, 143, kao utjecajnog ističe posebno Vincenta iz Beauvaisa (1190.-1264.), djelo Speculum majus, a posebno 11. knjigu Speculum docrtinale, posvećenu artibus mechanicis. Tiskano u 15. stoljeću. Kruft, 1986, 38-39.

${ }^{8}$,The main points od Alberti's functionalist-organic theory may be summarized as follows: (1) Architecture imitates the principles of art which are in nature's organic creations; and (2) just as one organic body differs from the other so too does one building differ from the other and for the same reason: end, purpuse, or function" (De Zurko, 1957, 144). Zauzima suprotan stav od Rudolfa Wittkowera, koji naglašava apstraktnu, matematičku definiciju ljepote kod Albertija, dok De Zurko ističe njegov humanistički pristup i razmatranje potreba kao i funkcija arhitekture. 
prijevodima, korištena je diljem Europe. Za sakralnu arhitekturu posebno je važna peta knjiga, Il Quinto libro d'architettura [...] nel quale si tratta di diverse forme de 'tempii sacri, objavljena u Parizu 1547. godine (Kruft, 1986, 80-81). Ne problematizirajući razloge, nastavlja se na renesansna promišljanja o centralnome tlocrtu kao idealnom za sakralne građevine, dakle potvrđuje formu uvjetovanu funkcijom i donosi čitav niz rješenja različitih centralnih oblika.

Ukratko izloženi primjeri teoretskih djela pokazuju dugu tradiciju bavljenja odnosom forme i funkcije u arhitekturi. Na nju se oslanja i barokno razdoblje, no donosi i nova pravila. Postavlja se i novi zahtjev kojega arhitektura mora ispunjavati, ona je sada prije svega u službi insceniranja moći, crkvene ili vladarske. Najvažniji tipovi barokne arhitekture stoga su crkva i dvorac, odnosno palača. U svim razdobljima, a posebno u baroku, „,arhitektura je umjetnički medij u kojemu se najbolje može izraziti novoprobuđena želja za reprezentacijom" (Brucher, 1983, 16), ona je snažno sredstvo prikazivanja moći, ugleda i položaja naručitelja, na što ukazuje Cesare Ripa (1555. -1622.) - u knjizi Iconologia za prikaz Magnificenza (1603.) koristi ženski lik koji drži model arhitekture u rukama, hrama (crkve) ili palače. Naručitelj tako pokazuje svoj status arhitekturom, a istovremeno se taj status kod promatrača uvijek iznova gradi upravo veličanstvenošću arhitekture - dvorac u Versaillesu ili nova crkva sv. Petra u Rimu pokazuju moć i ugled kralja, odnosno pape, ali istodobno su i važan sastavni dio njihove moći. Barokna arhitektura često je teško razumljiva suvremenom promatraču, za njezino razumijevanje potrebno je razmotriti bitno izmijenjene okolnosti u kojima je ta arhitektura nastala, kao i izvornu funkciju uvjetovanu specifičnim kulturno-povijesnim kontekstom razdoblja. Ono je određeno prije svega protureformacijom u katoličkom dijelu Europe, koja uvjetuje bitne promjene u sakralnoj umjetnosti i donosi nova rješenja gradnje crkava. Procesi promjena društvenog uređenja i učvršćivanje središnje (kraljevske) vlasti, koje dosežu vrhunac u apsolutističkoj Francuskoj Luja XIV., rezultirat će pak novim oblicima reprezentativne arhitekture. Na nekoliko primjera razmotrit će se odnos forme i funkcije $\mathrm{u}$ baroku - profana arhitektura kao sredstvo reprezentativnosti te sakralna arhitektura kao funkcionalni okvir poslijetridentske liturgije.

$\mathrm{U}$ razmatranju odnosa forme i funkcije baroknog razdoblja profana je arhitektura daleko složenija. Barokni dvorac ispunjavao je nekoliko 
funkcija, ne samo stanovanje vlasnika i obitelji, nego je to i prostor reprezentacije, ali i „radno mjesto” vladara, što je odredilo dimenzije i oblike arhitekture. Dok se uspinjemo veličanstvenim stubištem Balthasara Neumanna (1687.-1753.) u Rezidenciji u Würzburgu (građena 1720.-1744.) kojega čini čak pet krakova, u složenom kretanju otvaraju nam se pogledi na različite dijelove Tiepolove freske s prikazima kontinenata; jasno je da to stubište nema samo praktičnu funkciju povezivanja etaža. „Rastrošnost u oblikovanju prostora i dekoracija pokazuje koliku je važnost imalo u ceremonijalu koji se odvijao na dvoru kao i specifičnom položaju njegova vlasnika (Bauer, 1992, 72-110). Reprezentativna arhitektura palača i burgova i u ranijim je razdobljima bila ključna komponenta vladarskog statusa, no u baroknoj apsolutističkoj Francuskoj za vrijeme Kralja Sunca, Luja XIV. (1661.-1715.) taj proces dolazi do svog vrhunca. Arhitektura kraljevskih rezidencija bila je pozornica i funkcionalni okvir dvorskom ceremonijalu (Burke, 2009, 86). Raskošne građevine doprinose njegovoj slavi i ugledu kao i vojne pobjede, kako to jasno iskazuje ministar Jean-Baptiste Colbert (1619.-1683.)9. Vrhunac je svakako rezidencija u Versaillesu, koja se od skromnog lovačkog dvorca tijekom nekoliko desetljeća razvila u najveću baroknu rezidenciju u Europi, nastalu kao rezultat pomno promišljene umjetničke politike i državnoga pokroviteljstva (Bauer, 1992, 27 i d.). U nepreglednom nizu prostorija krila Versaillesa, s Chambre $d u$ Roi u središtu, prostorna organizacija utjelovljuje centralističku vlast, što je naglašeno i povišenim položajem dvorca koji dominira okolinom. Prostrani pomno oblikovani vrtovi i park pokazuju nadmoć vladara i nad prirodom, kojom vlada kralj kao Apolon.

Osim u kraljevskim rezidencijama, i u arhitekturi plemićkih dvoraca javljaju se zanimljive promjene koje neposredno odražavaju nove funkcije i načine njihova korištenja, odnosno života u dvorcima. Prostorna kompozicija u raskošnom dvorcu ministra financija Nicolasa Fouqueta u Vaux-leVicomteu (građen 1657.-1661.) ${ }^{10}$ zrcali razvoj nove organizacije dvoraca

${ }^{9}$,Votre Majesté sait qu'à defaut des actions éclatantes de la guerre, rien ne marque davantage la grandeur et l'esprit des princes que les bâtiments et toute la postérité les mesure à l'aune de ces superbes maisons qu'ils ont élevées pendant leur vie”, cit. prema Höpel, 2010, 19.

${ }^{10} \mathrm{Na}$ njegovoj izgradnji i opremanju bili su angažirani najvažniji umjetnici razdoblja: Louis Le Vau (1612.-1670.), Charles Le Brun, dok vrtove radi André Le Nôtre (1613.-1700), a velikom svečanošću na kojoj je prisustvovao i Luj XIV. obilježeno je dovršenje dvorca. 
koji su započeli Salomon de Brosse (1571.-1626.) i François Mansarta (1598.-1666.), a koji će prevladavati kroz cijelo barokno razdoblje: corps de logis, tzv. dio za stanovanje se izdvaja, a niža bočna krila flankiraju dvorište cour d'honneur, zatvoreno ogradnim zidom, dok se iza građevine prostiru geometrijski organizirani vrtovi. U unutrašnjosti corps de logisa ističe se središnja os koju čine ulazni dio, raskošno stubište i velika središnja dvorana - salon, a sa strana su simetrično raspoređeni appartements za stanovanje, koje čine mali salon, predsoblje i soba. Oblikovanje i dimenzije tih prostorija neposredno su uvjetovane njihovom funkcijom. Francuska postavljanjem novog standarda arhitekture rezidencija i njihova opremanja postaje uzor svim europskim vladarima, a smišljeno medijsko korištenje arhitekture u propagandne svrhe, posebno kraljevskih rezidencija, preko opisa kraljevskih svečanosti u novinama i grafičkih prikaza iz Kraljevskog kabineta, inicira pravi boom izgradnje palača i dvoraca u Europi (Burke, 2009, 194). Veliku su ulogu imali i traktati francuskih arhitekata koji postaju mjerodavni za pitanja arhitekture dvoraca, posebno ladanjske arhitekture, primjerice djelo Jacquesa Françoisa Blondela (1705.-1774.) De la Distribution des Maisons de Plaisance, et de la Décoration des Edifices en General, 1737.-1738. U srednjoj Europi preuzet će se francuski uzori u arhitekturi dvoraca, osobito za Lustschlösser, čiji pregled donosi utjecajan traktat Paula Deckera (1667.-1713.) Der fürstliche Baumeister ${ }^{11}$.

Svojevrsni početak i kraj sakralne arhitekture baroknog razdoblja označile su dvije važne odredbe. Njezin početak „otvaraju” upute o gradnji donesene na Tridentskome koncilu, a „kraj” razdoblja, kada govorimo o srednjoeuropskom kontekstu, predstavlja usvajanje prosvjetiteljskih ideja izraženih u dekretu o gradnji crkava cara Josipa II. Oba su zanimljiva u ovome kontekstu jer se bave formom crkvenog prostora, koja je naglašeno u službi funkcije. U analizi odnosa forme i funkcije pristup sakralnoj arhitekturi u određenoj je mjeri lakši, jer je češće ostala sačuvana njena izvorna namjena. No liturgija baroknog razdoblja uvelike se razlikuje od današnje, kao što se razlikuju i njeni korisnici, ali i društveni kontekst u kojem se

${ }^{11}$ Fürstlicher Baumeister/ Oder Architectura Civilis, Wie Grosser Fürsten und Herren Palläste/ mit ihren Höfen/ Grotten/ Orangerien/ und anderen dazu gehörigen Gebäuden füglich anzulegen und nach heutiger Art auszuzieren (...). 1711.-1716. 
odvija. Ključnu ulogu u oblikovanju barokne liturgije imala je protureformacija, preciznije upute za novu liturgiju i oblikovanje sakralnog prostora donesene na Tridentskom koncilu (1545.-1563.) ${ }^{12}$. U crkvama isusovačkog reda nastaju prva rješenja prostora koja ispunjavaju te zahtjeve. Promjene u korištenju sakralnog prostora nastupile su brzo, posebno u usporedbi s profanom arhitekturom u kojoj se one znatno sporije odvijaju.

Milanski biskup Karlo Boromejski (1538.-1584.) objavio je 1577. godine Instructiones fabricae et supellectilis ecclesiasticae, upute o gradnji crkava i oblikovanju prostora prilagođenog potrebama nove liturgije. Posebice dio De ecclesiae forma bitno je odredio razvoj sakralne arhitekture (Wittkower, 1982, 39-42; Kruft, 1986, 103 i d.). Uz naglašavanje važnosti odabira primjerenog smještaja i okruženja, istaknute pozicije, oblikovanja pročelja, dimenzija crkve primjerene potrebama vjernika, ali i posebnim svetkovinama, povijesno umjetnička literatura u pravilu kao najvažnije ističe odredbe o odabiru tlocrtnoga oblika crkve. Napušta se renesansno tumačenje centralnoga oblika kao idealnog i preporuča se vraćanje longitudinalnom tlocrtnom obliku latinskog križa:

Since many plans are possible, the bishop must make his decision after consulting with an expert architect and taking into account the nature of the site and the size of the building.

The cruciform plan, going back almost to apostolic times, and as seen in the major basilicas of Rome, built in this way, is to be preferred. The round edifice was once used for pagan temples and much less among Christian peoples.

Every church, then, and in particular those requiring an imposing appearance, ought preferably to be built in the form of a cross. There are various types, such as for example the oblong one, which is most commonly used. The other types are rarer.

Therefore, where possible, the oblong cross plan should be used in every church to be built, whether it is a cathedral, collegiate or parish church. Where the site requires a plan that differs from the oblong form, the advice of the architect can be followed subject to approval by the bishop. (Cit. Borromeo, 2011.)

Tim je odredbama jasno određeno koja je forma primjerenija funkciji i koju treba nastojati koristiti. Longitudinalni tlocrtni oblik crkve svakako

${ }^{12} \mathrm{O}$ Tridentskome koncilu i njegovom utjecaju na umjetnost baroknog razdoblja u Hrvatskoj, v. Cvetnić, 2007. 
je bio pogodniji, zbog prostranosti, potrebe smještaja što većeg broja vjernika i jasnog usmjerenja prema oltaru. Svetište se posebno naglašava opremom i osvjetljenjem kao najvažniji dio crkve. Idealni oblik crkve preuzima se iz arhitektonske tradicije, longitudinalni bačvasto svođeni brod flankiran s po tri para kapela, naglašenim križištem s velikom kupolom $i$ istaknutim svetištem koji koristi već Alberti u crkvi s. Andrea u Mantovi (1470.). U matičnoj crkvi isusovačkog reda u Rimu Il Gesù (Giacomo Barozzi da Vignola od 1568., dovršio Giacomo della Porta) taj model prilagođava se potrebama nove liturgije - longitudinalan brod s kapelama i naglašenim križištem s moćnom kupolom kroz koju dopire snop svjetla koje čini dramatičnu cezuru prije svetišta na kojem se odvija prikazanje - i postaje uzor za gradnju crkava te će kao malo koja druga građevina imati utjecaj na sakralnu arhitekturu baroknog razdoblja (Norberg-Schulz, 1986, 13, 62).

U samome oblikovanju prostora crkve očituju se tendencije postizanja theatrum sacrum učinka. Raskošne privremene scenografije, appara$t i$, machine ili teatro sacro postavljale su se, učestalo u crkvama isusovačkog reda, prilikom svečanosti i pobožnosti, a posebno za pobožnosti Quarantore, Četrdesetnog klanjanja Presvetom Sakramentu. Projektirali su ih vodeći arhitekti razdoblja, od Gian Lorenza Berninija (1598.-1680.) i Pietra da Cortone (1596.-1669.) do Carla Rainaldija (1611.-1691.), a vrhunac sceničnog oblikovanja prostora dostignut je u zidnim slikama i oltarima isusovačkog slikara i arhitekta Andree Pozza (1642.-1709.) ${ }^{13}$. No te scenografije i oprema uvelike su utjecali i na oblikovanje prostora. Naglašeno perspektivno oblikovanje u brodu crkve ostvaruje se u nizanju otvora kapela, lukova i pojasnica, a posebno oltara u bočnim kapelama koji poput kulisa uokviruju pogled prema glavnome oltaru, odnosno svetištu, kako je ostvareno i u prvoj baroknoj crkvi u Hrvatskoj, zagrebačkoj crkvi sv. Katarine (građena 1620.-1632.). Neposredan odraz nove funkcije svetišta i glavnoga oltara, odnosno naglašena važnost euharistije i otajstva transsupstancijacije u poslijetridentskoj liturgiji, odražava se u njihovome novome oblikovanju (Cvetnić, 2007, 152 i d). Kao i na suvremenim scenografijama, arhitektonskim okvirom istaknuta je središnja scena i najvažniji

${ }^{13}$ Cf. Schütze, 2005, 117-138. O apparatima za Quarantore v. Bauer, 1992, 274; Premerl, 2009, 421-427. Ubrzo se rješenja raskošnih scenografija naglašene perspektive šire preko brojnih opisa i grafika svim krajevima katoličke Europe, a tome je posebno doprinio Pozzov traktat Perspectivae pictorum et architectorum (1693., 1698.), Wittkower, 1982, 366. 
sadržaj, odnosno svetište crkve. Arhitektonski okvir svetišta, trijumfalni luk koji odvaja brod i svetište postaje sve naglašeniji, posebno u crkvama isusovačkog reda. U crkvi sv. Mihaela u Münchenu, svojevrsnom rasadniku rješenja za srednjoeuropsku umjetnost baroka, trijumfalni luk je naglašenih dimenzija, poput okvira pred osvijetljenim svetištem. Velika važnost trijumfalnom luku dana je, naravno, i u postojbini protureformacije, sjevernoj Italiji, posebno u projektima Lorenza Binaga, koji u crkvi S. Alessandro iz 1601. trijumfalni luk oblikuje kao prostorno suženje pred svetištem.

Ta načela oblikovanja prostora s naglašenim sceničnim učinkom nizanja pojasnica i likova kapela te isticanjem svetišta nastavit će se i u 18 . stoljeću, samo nešto izmijenjenim sredstvima. Umjesto bačvastog svođenja broda, u arhitekturi srednjoeuropskog prostora prevladavat će kupolasti svodovi (tzv. češke kape), koji dodatno pojačavaju scenični učinak, a posebna je pažnja posvećena trijumfalnom luku. On postaje „svođeni slavoluk"14, oprostoren trijumfalni luk ${ }^{15}$, a primjenu će naći i u longitudinalnim (franjevačka crkva sv. Roka u Virovitici, 1752.) i u centraliziranim tlocrtnim rješenjima (crkva Majke Božje Jeruzalemske na Trskom Vrhu kod Krapine, 1751.).

Naglašena sceničnost i raskoš prostornog oblikovanja, složeni pogledi i vizure, pa i dramatično osvjetljenje, doživljavaju kulminaciju u sakralnoj arhitekturi jugoistoka srednje Europe sredinom 18. stoljeća. No istovremeno prodiru i sve snažnije prosvjetiteljske ideje, reformatorski duh i ovdje se uvukao, posebno potaknut nastojanjima cara Josipa II. (1741.-1790.) u brojnim reformama koje provodi u tom razdoblju po njemu nazvanom ,jozefinizam”. Brojnim odredbama nastoji smanjiti baroknu sceničnu raskoš u crkvama, ali i regionalne razlike, i stvoriti novi tip crkve koji će ispunjavati potrebe novog vremena i novog društvenog uređenja. Kao u malo kojem razdoblju do tada, u prvi plan dolazi zahtjev za praktičnim

${ }^{14}$ Pomalo nespretan termin ,svođeni slavoluk”, koji asocira na carsku antičku arhitekturu, hrvatska povijest umjetnosti preuzela je od slovenskog prijevoda njemačkog termina „,eingezogener Chorbogen” (Nace Šumi - prevodi s „obočni slavolok”; Šumi, 1961, 70, 94; preuzima Đurđica Cvitanović i prevodi kao „svođeni slavoluk”; Cvitanović, 1985, 75).

${ }^{15} \mathrm{Cf}$. Koepf, Binding, 2005, 481-482. Porijeklo svođenog slavoluka je u gotičkom uvučenom trijumfalnom luku. I u gotici označava početak svetišta, a ujedno služi i kao element koji savladava prostornu razliku jer je svetište redovito uže, često i niže od broda crkve. 
i utilitarnim oblikovanjem, crkve trebaju biti funkcionalne i pregledne. Smjernice za oblikovanje crkava koje odgovaraju novim potrebama jasno su zadane u dekretu cara Josipa II. iz 1785. godine, u kojem se ističe da oblikovanje mora biti ograničeno na „nužno, korisno i svrhovito”, ,im Übrigen soll sie (die Erbauung der Kirchen) sich nur auf das Nothwendige, Nützliche und Zweckmäßige, mit Hinweglassung alles Prunkes beschränken und soweit es jenen drei Eigenschaften unbeschadet geschehen kann, die möglichste Oekonomie zur Pflicht machen" (cit. prema Gelsinger, 2000, 63). Prema novom shvaćanju uloge crkve naglasak je pomaknut s raskošnih baroknih samostana na sustavno organiziranu i učinkovitu mrežu župnih crkava. U dekretu o crkvenim reformama Directiv-Regeln für das Pfarreinrichtungsgeschäft für das offene Land iz 1782. određeni su i kriteriji za osnivanje župa i gradnju crkava, pri čemu je broj stanovnika najvažniji (Gutkas, 1980, 173-176).

No ne treba zanemariti još jedan važan aspekt u odredbama o gradnji crkava, a to je naglašena uloga arhitekture kao važnog čimbenika u stvaranju „državnog arhitektonskog identiteta”, kako taj fenomen naziva austrijski povjesničar umjetnosti Christian Benedik (Benedik, 1994, 24). Državna kontrola nad gradnjom u čitavoj Monarhiji postaje sve prisutnija, a lokalne specifičnosti, pa čak i umjetničko stvaranje, dobivaju znatno umanjeni prostor djelovanja, koji ustupa mjesto prepoznatljivome državnom stilu. Da bi se provele sve te odredbe, u strogo ustrojenom birokratskom aparatu, uspostavlja se hijerarhijski organiziran sustav institucija koje provode odluke središnje vlasti (Heppner, 1994, 10). Bečki Hofbauamt, središnji ured za izgradnju, postupnim promjenama djelovanja, posebno u vrijeme uprave F.A. Hillebranda 1770-ih, postaje ured koji upravlja izgradnjom u čitavoj državi ${ }^{16}$, a njegove odluke provode podređena tijela u pojedinim zemljama Monarhije ${ }^{17}$. Jedna od glavnih zadaća Hofbauamta postaje

\footnotetext{
${ }^{16}$ Preimenovan je 1783. u Generalhofbaudirektion, a bio je u funkciji sve do 1848. godine. Iscrpan pregled u Benedik, 1994.

${ }^{17}$ U Hrvatskoj je nadležno bilo Kraljevsko ugarsko namjesničko vijeće, od 1723., a od 1767. do 1779. Kraljevsko vijeće za kraljevine Dalmaciju, Hrvatsku i Slavoniju, kada nadležnost preuzima Ugarsko namjesničko vijeće, sve do 1848. godine. U Zagrebačkoj, Varaždinskoj i Križevačkoj županiji su od 1761. do 1848. djelovali i građevinski uredi, u čijoj je nadležnosti bilo provođenje planova, kao i manji projekti. Izgradnja na području Vojne krajine bila je u nadležnosti Glavnog vojnog zapovjedništva za Hrvatsku, odredbe središnjeg ureda za graditeljstvo u slavonskoj Vojnoj krajini provodi Slavonische Gränitz-Bau Direction, koja
} 
stvaranje spomenutog ,jozefinskog državnog arhitektonskog identiteta”. Uz javne građevine velika važnost posvećena je upravo izgradnji crkava. U Hofbauamtu 1771. godine nastaju tipski planovi za crkve, Kichennormpläne, za dio monarhije pod Ugarskom dvorskom komorom ${ }^{18}$. Najveću će primjenu naći u prostorima koji su bili pod direktnom upravom Beča, u kojima je usred osmanlijskih osvajanja dokinut kontinuitet arhitektonskog razvoja, a posebno u krajevima pod vojnom upravom, kao što je Vojna krajina u Hrvatskoj. Izrađena su tri tlocrtna rješenja, longitudinalne trotravejne i dvotravejne crkve te jedno centralizirano rješenje, s centraliziranim svetištem. Svaki plan sastoji se od tlocrta, nacrta pročelja i presjeka nad kojim je zvonik. U sjeverozapadnoj Hrvatskoj, posebno u okolici Zagreba, veliku će primjenu naći centralizirani tip crkve: u župnoj crkvi sv. Nikole u Žažini (1778.), župnoj crkvi sv. Helene u Zaboku (1782.) ili u župnoj crkvi sv. Ivana Krstitelja na Novoj Vesi u Zagrebu (1786.). Na području Vojne krajine vojni zapovjednici nadgledaju i gradnju civilnih i sakralnih objekata, a podizali su ih u pravilu graditelji angažirani na izgradnji utvrda i vojnih objekata. Utilitarnost kao temeljno načelo gradnje jasno je iskazana u preciznim odredbama i uputama o primjeni pojedinog tipa te oblikovanju i dekoracijama, a glavni je kriterij odabira, uz naravno raspoloživa sredstva, broj vjernika. Crkve većih dimenzija i s primijenjenom, iako krajnje pojednostavljenom arhitektonskom plastikom, podižu se u mjestima s više od 1000 stanovnika, crkve srednje veličine, nešto jednostavnijeg oblikovanja, u mjestima s 600 do 800 stanovnika, a krajnje jednostavne crkve bez složenije raščlambe prostora i upotrebe dekoracija prikladne su za manja mjesta do 500 stanovnika. Jasnim uputama o gradnji crkava i planovima za tipske crkve, koje se posebno provode u područjima

je do 1783. imala sjedište u Osijeku, a zatim u Petrovaradinu. Nakon revolucije 1848. vojne krajine su pod upravom Hrvatsko-slavonskog zemaljskog zapovjedništva (Croatisch-Slawonische-Landes-Militar-Command), a gradnja prelazi pod nadležnost novog tijela, Carsko i kraljevsko građevinsko upraviteljstvo za Hrvatsku i Slavoniju (K. und K. Landes-Baudirektion für Kroatien und Slawonien) te Banskog vijeća, odnosno Odsjeka unutarnjih poslova koji je u nadležnosti imao i gradnju. Pregled institucija nadležnih za graditeljstvo v. Jurić, 2004, 514-516.

${ }^{18}$ Pohranjeni su u bečkom Austrijskom državnom arhivu, Drei Projekte für die Kirchen in den ungarischen Kameralherrschaften. Finanz- und Hofkammerarchiv, sign. AT-OeStA/ FHKA SUS KS, Rb-143/1-9, Kamerale Ungarn, Fasz. 33/3, Nr. 53 (Juni 1771.), objavljeni u Botica, 2011. 
pod vojnom, u manjoj mjeri i onim pod civilnom vlašću, novopodignute crkve koje se grade prema istim odredbama od Galicije i Banata do Vojne krajine, čine važan vidljivi znak prisutnosti središnje vlasti „,na terenu”.

Prikazane odredbe o gradnji obuhvaćaju tek mali dio široke teme odnosa forme i funkcije u baroknoj arhitekturi. Forma i dvorca i crkve strogo je određena njihovom funkcijom i specifičnim potrebama naručitelja. Barokni dvorac ima ključnu ulogu u stvaranju i potvrđivanju moći vladara, nizanje prostorija i ceremonijalna stubišta u dvorcima ujedno su i pozornica na kojoj se vladar prikazuje, ali i oblikovanjem strogo hijerarhijskih odnosa, istovremeno i gradi tu vlast. Novom liturgijom poslijetridentska crkva reinterpretira tip longitudinalne crkve s kapelama i kupolom nad križištem, a potpuno novo značenje daje se trijumfalnom luku. Kraj je razdoblja pak snažno određen nastojanjem za ujednačavanjem i prevladavanjem strogo utilitarnog pristupa arhitekturi, a opet s ciljem ostvarivanja i učvršćivanja državne vlasti.

\section{Literatura}

Bauer, H. (1992). Barock. Kunst einer Epoche. Berlin: Dietrich Reimer Verlag. Benedik, C. (1994). Organisierung und Regulierung des k.k. Generalbaudirektion und deren Landesstellen. „Das 18. Jahrhundert und Österreich. Jahrbuch der Österreichischen Gesellschaft zur Erforschung des 18. Jahrhunderts", br. 9, str. 13-28.

Borromeo, C. (2011). Instructiones fabricate et supellectilis ecclesiasticae (selection). Prev. E.C. Voelker. „Art history supplement”, vol. 1, br. 2, June. http://www.artproof.co.uk/issues/issue2/voelker. 6.06.2011.

Botica, D. (2011). „Dugo 18. stoljeće” u sakralnoj arhitekturi - tipologija sakralne arhitekture u sjeverozapadnoj Hrvatskoj i Štajerskoj u drugoj polovici 18. stoljeća i na početku 19. Stoljeća. U: Neznano iz pozabljeno iz 18. stoletja na Slovenskem. Ur. M. Preinfalk. Ljubljana: Zgodovinski inštitut Milka Kosa ZRC SAZU i Slovensko društvo za proučevanje 18. stoletja, str. 167-182.

Brucher, G. (1983). Barockarchitektur in Österreich. Köln: DuMont Verlag.

Burke, P. (2009). Ludwig XIV. Die Inszenierung des Sonnenkönigs. Berlin: Wagenbach Verlag.

Cvetnić, S. (2007). Ikonografija nakon Tridentskog sabora i hrvatska likovna baština. Zagreb: FF Press.

Cvitanović, Đ. (1985). Sakralna arhitektura baroknog razdoblja, gorički i gorsko-dubički arhiđakonat. Zagreb: Društvo povjesničara umjetnosti Hrvatske. 
De Zurko, E.R. (1957). Albert's Theory of Form and Function. „Art Bulletin”, vol. 39, br. 2., str. 142-145.

Gelsinger, M. (2000). Von der Beschränkung auf das „Nothwendige, Nützliche und Zweckmäßige" Josephinischer Kirchenbau in Oberösterreich. U: Kunstjahrbuch der Stadt Linz, Linz: Nordico Stadtmuseum Linz, str. 63-98.

Gutkas, K. (1980). Die kirchlich-sozialen Reformen. U: Österreich zur Zeit Kaiser Josephs II. Ur. K. Gutkas. Melk: Katalog izložbe, str. 173-176.

Heppner, H. (1994). „Bauboom” und „Aufbruchsstimmung”, Schlagworte oder Schlüsselbegriffe zum Verständnis des 18. Jahrhunderts. „Das 18. Jahrhundert und Österreich. Jahrbuch der Österreichischen Gesellschaft zur Erforschung des 18. Jahrhunderts", br. 9, str. 7-12.

Höpel, T. (2010). Das Modell Versailles. U: Europäische Geschichte Online (EGO). Mainz: Leibniz-Institut für Europäische Geschichte.

Jurić, M. (2004). Nacrti crkvenih zgrada u Hrvatskom državnom arhivu. Zbirka građevinskih nacrta i Zbirka planova. „Tkalčić”, br. 8, str. 511-549.

Koepf, H., Binidng, G. (2005). Bildwörterbuch der Architektur. Stuttgart: Kroener Alfred $\mathrm{GmbH}$.

Kruft, H.-W. (1986). Geschichte der Architekturtheorie. Von der Antike bis zur Gegenwart. München: Verlag C.H. Beck.

Norberg-Schulz, C. (1986). Baroque Architecture. New York: Electa/Rizzoli.

O'Gorman, J.F. (1991). Three American Architects: Richardson, Sullivan, and Wright, 1865-1915. Chicago: University of Chicago Press.

Premerl, D. (2009). Glavni oltar splitske katedrale - tipologija, ikonografija i hipoteza o naručitelju. U: Sic ars depreditur arte. Zbornik u čast Vladimira Markovića. Ur. S. Cvetnić, M. Pelc, D. Premerl. Zagreb: Institut za provijest umjetnosti Filozofskog fakulteta Sveučilišta u Zagrebu, str. 419-438.

Schütze, S. (2005). Die Ausstattung von Neu-St. Peter. U: Barock im Vatikan. Kunst und Kultur im Rom der Päpste 1572-1616. Ur. F. Buranelli. Leipzig: E.A. Seemann Verlag, str. 117-138.

Šumi, N. (1961). Ljubljanska baročna arhitektura. Ljubljana: Slovenska matica.

Wittkower, R. (1982). Art and Architecture in Italy 1600-1750. London: Yale University Press, Pelican History of Art. 